\title{
Opening Doors to Literature: People \& Stories / Gente y Cuentos
}

\author{
Ellen Gilbert, People \& Stories / Gente y Cuentos, USA
}

\begin{abstract}
People \& Stories/Gente y Cuentos (P\&S/GyC) is a non-profit literacy outreach organization with headquarters in the U.S. state of New Jersey (https: / / peopleandstories.org/). P\&S/GyC is guided by a belief in the power of literature to positively impact transitioning populations, such as halfway house residents, immigrants working toward citizenship, and veterans reintegrating into civilian life. Homeless parents and senior citizens are also invited to participate in P\&S/GyC's reading programs, which include oral readings and seminar-style discussions of literary short stories. The stories chosen for P\&S/GyC programs typically embody the best qualities of enduring literature: artistic richness, explorations of life complexities, wonders, and ambiguities. Participants learn to connect knowledge synthesized from their own life experiences with stories under discussion in an atmosphere of trust established by trained facilitators. P\&S/GyC's beginnings date back to 1972, when founder Sarah Hirschman invited a group of Puerto Rican women in Cambridge, Massachusetts to engage with their cultural heritage through reading literature in their first language-Spanish. English reading groups were added to P\&S/GyC's design in 1986, and today the program collaborates with social service organizations, such as the Harvard Humanities and Liberal Arts Assessment Lab, and other partner sites in the states of New Jersey, New York, and Pennsylvania. In 2016, the National Endowment for the Humanities recognized the extraordinary work of P\&S/GyC by funding a 30-month expansion program called "Reading Deeply in Community," partnering with ten public library systems around the country.
\end{abstract}

Keywords: community engagement; literacy; orality; outreach; reading groups

Publication Type: special section publication

\section{Introduction}

D uring the 1960s and 1970s, Sarah Hirschman (1921-2012), a classically educated philosopher, convened Latino immigrant reading groups in New York and Massachusetts, gradually introducing additional forms of community work as part of the program design. The Spanish language reading program was then formally launched in 1974, when the Hirschmans moved to New Jersey. Sarah formally established Gente y Cuentos (meaning "people and stories") with a group of Latino immigrants in various localities throughout the state "to encompass sites in learning centers, libraries, and prisons" ("Obituaries," 2012). Over the course of more than 40 years, English language reading programs were incorporated, adding the moniker "People \& Stories" to the organization's name. People \& Stories/Gente y Centos (P\&S/GyC) has served more than 400 participants across the world, including reading groups in France and Argentina. The P\&S/GyC method of collaborative reading and discussion reaches individuals who are often going through some kind of life transition, and the group-oriented structure of the

The International Journal of Information, Diversity, \& Inclusion, 3(2), 2019

ISSN 2574-3430, jps.library.utoronto.ca/index.php/ijidi/index

DOI: $10.33137 /$ ijidi.v3i2.32595 
program encourages adults to continue with their education while strengthening their literacy skills for broader application in navigating their personal and professional lives.

To contextualize Sarah Hirschman's passion for founding and promoting P\&S/GyC, we need to understand her identity and agency in relation to using reading as a means of cultural empowerment. She was born in Lithuania in 1921 and just like her husband, the distinguished social scientist Albert O. Hirschman (1915-2012), Sarah had an international upbringing. She grew up in Paris, studying philosophy with Simone de Beauvoir, and completing her university education in philosophy and French literature at the University of California-Berkeley in the U.S. In 1941, Sarah and Albert (whom she met at Berkeley) married, and from that point forward, their lives were a remarkable collaboration. Accompanying Albert on an early work assignment that took him to Colombia, Sarah became fluent in Spanish, studied anthropology, and was introduced to some of the social problems that would later inform her work.

Brazilian philosopher and educator Paulo Freire was an influential voice for Sarah. At a 1969 seminar that Freire gave at Harvard University, Hirschman was struck by his conviction "that people could acquire new knowledge only as it becomes meaningfully related to their life" (Hirschman, 2009, p. 12). Sarah applied Freire's ideas to reading, asking:

Could a beautiful, multivocal, short story exercise similar powers . . . could a literary text stimulate the imagination and set in motion a number of links to private experiences? And could members of a group who read and discuss a story together transform these deeply felt private reactions into a more public discourse that could be a dialogue? (p. 12)

With this insight, Hirschman founded P\&S/GyC in 1972.

\section{P\&S/GyC Program Design}

Following Freire's lead, $\mathrm{P \& S} / \mathrm{GyC}$ is designed in such a way that coordinators are trained to avoid the typical "teacher expert" role; instead of imparting knowledge, coordinators try to encourage participants to glean ideas and skills from texts that could be applied in real life. Coordinators read short story texts in advance and then, following the Freirean approach, they reflect on their own reader responses and insights and prepare discussion questions for each group. Reading groups run in eight-week sessions, giving coordinators enough time to become acquainted with readers' life narratives and reading tastes and interests. Coordinators take each group's unique interests into consideration to prompt their preparations for choice of the next text and accompanying discussion questions for the following week.

$\mathrm{P \& S} / \mathrm{GyC}$ reading group sessions typically begin with the coordinator reading aloud the chosen short story of the week. Participants listen and then respond through open group discussion, giving their own interpretation of texts. Through active listening to the differing ideas offered by other group members, they become more aware of their own responses to, understanding of, and ideas about the selected readings. The dialogue that emerges helps participants consider and critique characterizations, literary tropes, and cultural or social stereotypes; have empowered voices; and refine critical and analytical thinking skills that can be applied in their daily lives of individuals in transition. Because this decentralized reading model works to collaboratively build knowledge, observers are sometimes surprised that P\&S/GyC participants at a prison or homeless shelter discuss literary metaphors by James Joyce or Chinua Achebe with

The International Journal of Information, Diversity, \& Inclusion, 3(2), 2019

ISSN 2574-3430, jps.library.utoronto.ca/index.php/ijidi/index

DOI: $10.33137 /$ ijidi.v3i2.32595 
the same ease as any other aspect of the group-oriented conversation.

For the P\&S/GyC model, the choice of a story is a crucial starting point. To build literacy skills, stories work best when they are brief, told in the first language of the participant group, have relatable content, and are capable of stimulating ideas. Sarah Hirschman drew on her wealth of literary knowledge, starting with great Latin American writers and later incorporating stories originally published in English and translations. Novels with dialectal dialogues were the greatest favorites with reading groups. Since many multicultural titles were read by various P\&S/GyC reading groups over the years, there exists an extensive online bibliography accessible to $\mathrm{P \& S} / \mathrm{GyC}$ community members; it is organized by language and accessible by author or title.

Although the bibliography includes prompts to help reading group coordinators facilitate group discussion, coordinators are encouraged to work through the P\&S/GyC methodology of reflexivity to integrate their own reading responses and insights into the story, especially as they prepare discussion questions for each class. Growing familiarity with members of the class as the eightweek session continues enhances the coordinator's ability to ask evocative questions and, of course, to compare and contrast ideas raised by stories in the previous weeks.

The P\&S/GyC model is framed around five story categories:

1) "poetics"

2) locating "tensions and contrasts"

3) "finding shadows"

4) "issues and themes," and

5) “life experience” (Hirschman, 2009, p. 27-42)

Participants receive a copy of each story, which they are often seeing for the first time. The coordinator reads the story through, and then what many of us call "the magic" begins: Together, participants delve into the story, share their reactions to it, and engage in mutual support by listening to one another's contributions. They discuss how the story relates to their own questions, ideas, and experiences. Readers experience what Roland Barthes (1977) calls plaisir [pleasure] in reading, where reading is "a pleasure . . . linked to cultural enjoyment and identity" (p. 9). The novelist and Iraqi War veteran Kevin Powers (2018) has described his own experience with literature at a very low point in his life:

My tether to the world outside my mind was made stronger by other books, until I came to the belief that the whole range of human experience, including suffering and pain, when witnessed or shared, could be transformed into a kind of transcendent awe. (p. SR5)

P\&S/GyC participants have consistently experienced empowering responses to literature as described by Powers and Barthes.

\section{Accountability}

P\&S/GyC's teaching style was developed over time and is carefully delineated in Hirschman's

The International Journal of Information, Diversity, \& Inclusion, 3(2), 2019

ISSN 2574-3430, jps.library.utoronto.ca/index.php/ijidi/index

DOI: $10.33137 /$ ijidi.v3i2.32595 
2009 book People and Stories / Gente y Cuentos. The book, along with other materials, is used in twice-a-year training sessions with English- and Spanish-speaking P\&S/GyC coordinators who lead 15-20 participants in once-a-week collaborative reading engagement sessions of 1.5 hours for eight weeks.

To date, P\&S/GyC boasts over 400 participants with meaningful outcomes. P\&S/GyC Executive Director Cheyenne Wolf reports that from about 420 adult participants:

- $86 \%$ strongly agreed that they want to "read more after this program";

- $83 \%$ reported that "reading and discussing the stories helped [them] notice new things about [their] opinions and beliefs";

- $\quad 76 \%$ said that they had "learned new strategies for handling situations that [they] may encounter";

- $92 \%$ agreed that "literature helps people understand themselves, others, and the world";

- $81 \%$ believed that discussing stories "made it easier to share" their own experiences; and

- $84 \%$ of the participants came out with "more confidence in my ability to read and interpret stories." (Wolf, 2018)

Anecdotal evidence consistently points to profoundly felt changes that take place as a result of participation in P\&S/GyC sessions. Program evaluations include ample space for participants' comments, and coordinators routinely report on the highlights of each session. Videos, prepared with the approval of cooperating facilitates and including only informed participants who have given their written consent to be photographed, can be highly influential. Senior adults, an important population served by $\mathrm{P \& S} / \mathrm{GyC}$, were the focus of a recent telecast in a local news series on the "Art of Aging," where participants shared positive testimonies about P\&S/GyC. The segment was filmed at a senior citizen center where P\&S/GyC holds regular programming (Edwards, 2018).

Encouraged by large and small grants from individual and corporate donors and, most importantly, by the feedback of P\&S/GyC participants and coordinators, several programs have evolved into new directions. Mindful of the powerful evidence that young children who are read to at home have higher success rates in school, the Fall 2017 session of P\&S/GyC at HomeFront's Family Preservation Center (New Jersey) included an added component: Participants were reminded, each week, of the importance of reading to their children and encouraged to use the well-stocked, well-lit library on the Center's second floor.

\section{Collaborations}

$\mathrm{P \& S} / \mathrm{GyC}$ integrates its programs with partner organizations that often focus on critical life transitions. These life transitions include prisoners moving to probation; halfway house residents re-joining community; at-risk youth in alternative education programs; adults enrolled in adult education programs; immigrants working toward citizenship; veterans re-entering civilian society; and seniors moving to new stages of life. Overhead costs for an eight-week series of the

The International Journal of Information, Diversity, \& Inclusion, 3(2), 2019

ISSN 2574-3430, jps.library.utoronto.ca/index.php/ijidi/index

DOI: $10.33137 /$ ijidi.v3i2.32595 
$\mathrm{P \& S} / \mathrm{GyC}$ method and design are relatively low, averaging about $\$ 3,300$ USD per session, and often less if the P\&S/GyC coordinator is a volunteer.

Cooperative arrangements with Princeton University's Program for Community Engaged Scholarship (ProCES) also show considerable promise. The goal of ProCES is to encourage research projects involving students and community organizations working on such issues as healthcare, housing, education, economic development, homelessness, hunger, immigration, and environmental conservation. Most recently, P\&S/GyC sessions at a local senior center offered valuable field experience for students in a ProCES-sponsored "Medical Humanities" class (ANT/HUM/Medical Humanities, Princeton University, 2018).

One of the enduring collaborations was between P\&S/GyC and the Princeton Public Library (New Jersey), in October of 2018, when the library celebrated its 25th anniversary of being a P\&S/GyC site. In response to criticisms that the Princeton Public Library P\&S/GyC group does not represent a "typical" P\&S/GyC audience, P\&S/GyC Board Vice President Constance Hassett pointed out that long-term members are not "underserved" in the sense of being "fiscally challenged," but rather they are not a community that is "over-served" (Hassett, 2018). Hassert stated that the participants "clearly feel that P\&S/GyC gives them, as members of a diverse Spanish-speaking diaspora, something of broad cultural value that they don't find elsewhere." Finally, Hassett shared that

"although my Spanish is rudimentary as best, I did hear: (1) how differently participants spoke Spanish and, (2) how often they expressed gratitude for the way Angelica [the P\&S/GyC coordinator at Princeton Library] explains diction, idioms and meanings that are specific to one country's speakers or another. Valuable cultural bonding is going on!" (Hassett, personal communication, October 27, 2018)

\section{Words of Encouragement}

In addition to the growing empirical evidence about the effectiveness of the literature-based reading groups, a constant stream of publications in both scholarly and popular literature provides P\&S/GyC with well-chosen words of encouragement. The shared reading aloud of stories at P\&S/GyC sessions is key, and award-winning authors Ursula K. Le Guin and Larry McMurtry speak to this phenomenon: "Oral performance is irreproducible," observed Le Guin (2004, p. 201); in his memoir, Walter Benjamin at the Dairy Queen, McMurtry (1999) suggested that Walter Benjamin's "description of the way good stories are told and passed on presupposes a certain human and cultural density. There must be people gathered in a place-ideally, perhaps, in an artisan's shop-to listen to the storyteller and to repeat the story in their turn" (p. 23). As Le Guin said, "Words are events, they do things, change things. They transform both speaker and hearer; they feed energy back and forth and amplify it. They feed understanding or emotion back and forth and amplify it" (2004, p. 199).

\section{Conclusion}

Respect for the diverse ways in which we, human beings, read our worlds through experience, through language, through literature, and then through the sharing of these essentials with each other, creates a keen awareness of our shared humanity. This heightened mutual awareness of the diversity of human knowledge and experience has always been a key component of P\&S/GyC programs. It is hoped that future community-based literacy programs like P\&S/GyC will examine

The International Journal of Information, Diversity, \& Inclusion, 3(2), 2019

ISSN 2574-3430, jps.library.utoronto.ca/index.php/ijidi/index

DOI: $10.33137 /$ ijidi.v3i2.32595 
intergenerational literacy among immigrants, continue to explore the effect of reading and discussing short stories about participants' identities, and more specifically identify the benefits that reading programming brings to different populations including teens at risk, senior adults, incarcerated individuals, and chronically ill patients in hospitals and rehabilitation facilities.

\section{References}

A. Colorni-Hirschman International Institute. (n.d.) Retrieved from https://colornihirschman.org/our-classics

Barthes, R. (1977). Image, music, text. New York, NY: Hill \& Wang.

Edwards, T. (2018, October 9). Art of aging: 'People and Stories' brings seniors together through reading. Retrieved from https://6abc.com/health/people-and-stories-brings-seniorstogether-through-reading/4447133/

Hirschman, S. (2009). People and stories / gente y cuentos: Who owns literature? Communities find their voice through short stories. New York, NY: iUniverse.

Le Guin, U. K. (2004). The wave in the mind: Talks and essays on the writer, the reader, and the imagination. Boulder, CO: Shambhala.

McMurty, L. (1999). Walter Benjamin at the Dairy Queen: Reflections on sixty and beyond. New York, NY: Simon \& Schuster.

Obituaries 1/18/12. (2012, January 18). Retrieved from http://www.towntopics.com/wordpress/2012/01/18/sarah-hirschman/

Powers, K. (2018, June 17). What kept me from killing myself. The New York Times, p. SR5.

Wolf, C. (2018, October 10). P\&S/GyC: Impact at a glance. Report to Board of Trustees. http://www.peopleandstories.org

Ellen Gilbert (ellendgilbert@gmail.com) is a People \& Stories / Gente y Cuentos facilitator. She has a doctorate in Library Science from Columbia University, and has published books and papers on American publishing history, libraries, and intellectual freedom.

The International Journal of Information, Diversity, \& Inclusion, 3(2), 2019

ISSN 2574-3430, jps.library.utoronto.ca/index.php/ijidi/index

DOI: $10.33137 /$ ijidi.v3i2.32595 